\title{
Criteria for Housing Design with Emphasis on Comparison between Traditional and Today Contemporary Iranian Architecture
}

\author{
Tahereh Nasr ${ }^{1}$ \\ ${ }^{1}$ Department of Architecture, Shiraz Branch, Islamic Azad University, Shiraz, Iran \\ Correspondence: Tahereh Nasr, Ph.D.; Assistant Professor, Department of Architecture, Shiraz Branch, Islamic \\ Azad University, Shiraz, Iran. E-mail: Soha_nasr@yahoo.com; nasr@iaushiraz.ac.ir
}

Received: March 1, $2016 \quad$ Accepted: September 19, $2016 \quad$ Online Published: November 30, 2016
doi:10.5539/jsd.v9n6p182
URL: http://dx.doi.org/10.5539/jsd.v9n6p182

\begin{abstract}
Settling in the cities and the numerous efforts being made for massive supply of houses in a short time period, makes difficult the access to a pattern as appropriate for family life with increase in concentration in building construction, the individual and family borders, too, are neglected.

Though due to the extensiveness and complexity of the concept of housing, one cannot give a comprehensive, unique definition of it, but the housing, as a shelter, is regarded as the primary and basic needs of the family.

House as a place for relaxation and comfort and a shelter for removing tiredness has been a peace and security locality from a long time ago. House demand is one of the most essential human`s demands. According to Article 31 of fundamental law of Islamic Republic of Iran also, possessing a suitable house is considered as the right for every person and every Iranian family. House not only as a shelter, but also as a place for humans raise, has a great importance in the initial and most fundamental society union, namely family.

Identifying the identity and investigating the residential complexes in regard to the aesthetics implies the precise and conscious observing and noticing their beauties and or ugliness.
\end{abstract}

Main Questions in this paper are:

- What are the consequences of disregarding the identity of today's housing architecture, especially the architecture of the ancient towns?

- Can the components of Iranian traditional architecture be applied in today contemporary residential architecture and be effective to create a sense of place?

So the main purpose of this article is Pathology of Today Contemporary Iranian housing Architecture and Comparison with traditional Iranian architecture.

The method explored is a descriptive-analytical and field method to gather information and documents are available. The impact of known factors and variables in Iranian contemporary and traditional residential architecture has been evaluated and compared.

Accordingly, having some criteria for achieving a suitable house design pattern is essential in a way that makes it possible to understand all its visual embodiments and identify its identity.

This research also state the reasons for disability of today's architecture and urban development against house problem and recommend some criteria for achieving a house design pattern after an overview of the definition of housing and examination of Iranian housing.

Keywords: housing, identity, Iranian Islamic traditional housing, Iranian today residential architecture, criteria for housing design

\section{Introduction}

Housing, as a basic need of man, has found different meaning in different natural and man- made environment and any community has given a special form to it depending on its needs and capabilities its economic, social and cultural possibilities and limitations in any of different time period. However despite of that above mentioned differences, housing in any community has had an excellent, sacred concepts, with supply of which, man has achieved his "being" and has experience and life in that "being". In other words, that quality of 
settlement has given meaning to the quality of man's being.

The reality of the physique of the town at a large scale consists of visual conceptions of the town, such as the town gates, the physical sketch or solids and voids, the outline and the profile of the town at a distance and in a medium scale, or "the image of the city", it consists of factors such as the sign, the road, the edge, the node and the district, while in a small scale or "the fact of the town" consists of factors such as the view, the space and the urban furniture these factors, on the whole, represent the visual spirit of the town.

Adding the people and the activities and kinetic characteristics of the town and other factors such as the sounds and the odor to the above factors gives live lines to the visual spirit of the town, which may be divided into spirits such as residential, commercial, administrative, religious, recreational, academic, etc.

The panorama, enclosure, the street and urban furniture are among main recognized criteria in urban planning for realization of principles of aesthetics in the town and residential complexes (Whittick, 1974).

The distinctions between visual effects of residential complexes and the economic, social and cultural relation of residents of any of them, give a special identity to each individual complex. Desirability of the environment for living, the mind and the spirit, and happiness and joy of residents of each complex depends on higher development of the community as regards economic, social and cultural contexts generally and more beauty in the visual effects of the complex, specially.

\subsection{Main Question}

How do humans interact with the environment and what is the sense of relaxation and comfort in their dwellings?

What are the consequences of disregarding the identity of today's housing architecture, especially the architecture of the ancient towns?

Can the components of Iranian traditional architecture be applied in today contemporary residential architecture and be effective to create a sense of place?

\subsection{Hypotheses}

Examination of the effects of modern architecture on the traditional Iranian architecture is necessary for re-development of the forgotten pattern of the Iranian people's life in the past periods.

\subsection{Research Methodology}

The method explored is a descriptive-analytical and field method to gather information and documents are available. The impact of known factors and variables in Iranian contemporary and traditional residential architecture has been evaluated and compared.

\section{Basic Definitions}

\subsection{Housing}

The importance of housing residences in the fact that many of primary needs of each individual such as eating, passing leisure time, rest, etc., are met in it. The concept of housing, in addition to a physical place, encompasses the whole residential environment as well, which includes all services and facilities required for the living of the family and places for the individuals' employment, education and health (Nasr 2011).According to different views, the house finds its exact meaning in the three scopes of: structural, practical and social (Nasr 2011).

1) The house, in its structural meaning, has a status that represents technical evaluation.

2) The house, as a place for living, represent practical welcomes and enthusiasm, for the feelings of which, man is the unit of measurement and the focal point.

3) The house, as a family settlement, represents the symbolic image, the unit of measurement and the focal point of which has been developed in the form of the social core.

In the second summit of human settlement 1996 ( held at Istanbul, Turkey), the appropriate housing was defined as follows: an appropriate shelter is not just the person: an appropriate space, appropriate housing was defined as follows; an appropriate shelter is not just the presence of a roof over the head of any person: an appropriate shelter means appropriate comfort, appropriate space, appropriate physical access and security, ownership security, structural stability and duration, appropriate lighting, appropriate air- conditioning and heating system, appropriate primary infrastructure, such as water supply, health care and education, waste disposal, appropriate environmental quality, appropriate hygienic factors, appropriate position and accessible regarding work and primary facilities all of which should be supplied considering their affordability to the people. 
Indeed, the genera definition and concept of housing, is not just a housing unit, but encompasses the whole residential environment.

\subsection{Some View on Housing}

Farabi (tenth century AD), in his idea of the Utopia, divides housing into two categories: the partial housing (a residential unit) and the global housing (urban and rural settlements).This shows the presence of a relation that housing has with its superior entity, the city or the village.

The German philosopher, Martin Heidegger, with a qualitative outlook to the issue of housing, believes that the real crisis of housing does not resides in its paucity, but its real crisis resides in the mankind's searching for settlement selection before anything else. He knows living, settlement, construction, development and nurturing as synonyms. Therefore, the issue of housing, in a broader scale, is not separate from the territory and the geographical scope of the country (Sartipipoor 2004).

Le Corbusier believed that home is the cover that establishes the proper relation between the environment and the human biological phenomena. An individual or a family should live at home, that means to lie, to walk, to lie down, to see and to think (Le Corbusier 1946).

For Charles Moore house is the center of the world for their residents. It is the most prominent building to consolidate space (Moore 1974).

In Amos Rapoport's opinion since the construction of a house is a cultural phenomenon, form and spatial organization of it is heavily influenced by the culture which belongs (Rapoport 1969).

Main points about housing spatial organization in these scholars' view are shown in Fig.1.

\begin{tabular}{|c|c|}
\hline Main points & Housing spatial organization \\
\hline Human, Individual and Social Concepts & Spatial Perception \\
\hline Space and Activity Relationships & Spatial Organization \\
\hline $\begin{array}{c}\text { Methods of Defining, Differentiating or } \\
\text { Composition of the Space }\end{array}$ & Constituent Elements and Details of Space \\
\hline
\end{tabular}

Figure 1. Main points about housing spatial organization in scholars' view

\subsection{Examination of the Need to Hosing from Different Dimensions}

The need to housing has two dimensions: the quantitative and the qualitative ones. In the quantitative dimension, the need to housing consists of knowing the phenomena and matters that bring out the issue of lack of shelter and the degree of access to it, in the study of the quantitative dimension of housing, indeed, the degree of responding to the need to housing without considering its quality is in the order. In the qualitative dimension, there are issues and phenomena that are known as lack of housing, bad housing and what is the issue, is the type and the form of the need.

In examination of the qualitative dimension of the housing, the indicators in question are:

1) The desired form of the housing

2) The strength of the hosing

3) the security of the housing

4) The degree of access and the appropriate distance of residents to the physical facilities and services of the neighbourhood

5) Access to the nature and open green areas

6) Provision of the equipments and public utilities ( the infrastructure) required for the housing

7) Adjacency of the housing to adapted uses

In general, the seven factors mentioned to above are among the most important criteria and indicators in definition and explanation of the quality appropriate for housing, paying attention to which in construction, will make possible carrying out of all living activities of the residents easily and with the desired efficiency and will assist in a sustainable urban life, and the appropriate structure and form for the town and urban districts. 


\section{Characteristics of a Desired Living Environment in the Iranian Culture}

The traditional Iranian house has characteristics that distinguish it from the modern house. They are significant from two approaches: The form approach and the desirability of Iranian life approach.

\subsection{The Form Approach}

In the form approach, one can list the following characteristics:

1) The traditional Iranian house has the interior and the exterior spaces. The courtyard, "hayat', in a house in Persian is equivalent to "courtyard" in English. Today the term "house" is just used for the interior space, though a strong need and requirement still exists to the exterior space, as it were (Ardalan 2010, 149).

2) Protection of the family border was the main function of the traditional Iranian house represented different level of the private realm of house: from the 'covert" 9interior) world of women and children down to the more public and 'apparent" (exterior) world of the men and social concerns.

In the houses of today, one could say that private realm has been somehow sacrificed by economic and social needs. Positional- spatial relations being created, which at first were based on the need to a private realm, have been degenerated and minimized, little by little. The effectiveness and attractiveness of the past positionalspatial relation, too, have perished (Ardalan 2010, 149).

3) Living inside the space enclosed by courtyards of the traditional residential house, too, was an appropriate response to the notion of family security.

4) The garden of heaven" was the core of every Iranian house.

Architectural solutions and spatial response to the concept of dwelling architecture in Iranian historic homes are shown in Fig.2:

\begin{tabular}{|c|}
\hline $\begin{array}{c}\text { Architectural solutions and spatial response to the concept of home architecture in historic } \\
\text { homes }\end{array}$ \\
\hline $\begin{array}{c}\text { The flexibility of the space organization and the possibility of space extending and combining with } \\
\text { other spaces }\end{array}$ \\
\hline Privacy spaces \\
\hline The combination of component spaces
\end{tabular}

Figure 2. Main idea in Iranian traditional dwelling design

\subsection{The Describe Approach}

The Iranian house was being considered as the direct reflection of the traditional culture and the moral values of life.

From another view, one could mention to desirability of life in the Iranian culture.

The characteristics of a desirable living environment in the Iranian culture could be summarized as follows:

1) The house as a place of comfort:

The Iranian house is the place of living of its residents. The home is a place for residence.

The equivalent of; residence" in Persian, Arabic and even Hebrew is "sokounat", which means comfort and peace of mind. The word "sakina" is derived from the world 'sakan", which is the opposite of "movement", it means "rest": it is being used for soul's rest and peace, meaning "peace of mind" and not having internal stress in decision and will. Thus, the significance of the term 'saken "' (= at rest $>>$ resident), in addition to referring to the material dimension of life of man, or, in other words, the fundamental aspect of the human life. Therefore, both the material dimension of comfort and relation such as lack of noise and sound pollution and adjustment of the environmental condition are the requirements for a desirable housing, and the peace of mind against all factors that may disrupt the mental peace of man, are among the main feature of a desirable housing.

2) Identity:

The identity of man and its relation to the identities of the human belongings and work (including his housing), which may be interpreted as materialization of man's identity in his works and belongings, are the fundamental subjects of reflection of man. Thus, it would be natural that man's housing is somehow linked to his identity. In fact, acquiring a balanced individual and social and material and moral identity by man is an important indicator 
of in evaluation of the desirable housing.

3) Definition and distraction of realms and scopes:

The relation between the internal elements of housing as well as its relation to the spaces beyond it must necessarily both have specified, definite realms and the scope and the spaces linking these realms must be known. The distinction of realms, from keeping the house immune to problems and issues such as oversight by others, noise ingress, olfactory pollution ingress, other pollutions ingress and the possibility of transgress by aliens due to diminish in security are among significant subjects in designing and defining varied realms fora desirable housing.

4) Possibility for human living:

Any community, proportional to its culture, tends to live and act in different spaces and, establish special traditions and usages and activities in his own housing.

In view of the fact that the traditional Iranian housing in recent decades, in confronting with the structure of new urban planning, the life style and the construction pattern, could not resist and express itself and preserve its own identity, and with speeding up of the population growth and migration, unstudied and hasty encouragement to concentrated building construction, promotion of mass production and summarizing of all motivations for construction in commerce, gradually the relation between housing architecture and the characteristics and subtleties of the Iranian life was broken and for re-development of the forgotten model of the Iranian people's native life, with appropriate changes, with the lifestyle of today, paying attention to housing in the past Iranian architecture is necessary in some cases (Pirnia 1995, 157-164).

The differences between Iranian traditional and today contemporary Lifestyle and residential architecture are shown in the Fig.3:

\begin{tabular}{|c|c|}
\hline Iranian Contemporary lifestyles and homes & \\
\hline Reduce the spatial sensitivity citizens & \multirow{7}{*}{ 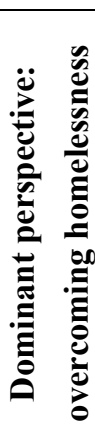 } \\
\hline $\begin{array}{l}\text { Reduce the participation in the determining the space privacy, } \\
\text { private and social attitudes }\end{array}$ & \\
\hline Reduce the sense of place for the home from the out vision & \\
\hline Devaluation of inside and outside interface spaces & \\
\hline Lack of attention to deep, center, direction and guidance of spaces & \\
\hline Reduced the level of infrastructure and Increased density & \\
\hline lack of attention to natural ventilation and light & \\
\hline
\end{tabular}

Figure 3. Iranian contemporary lifestyles and homes

\section{Examination of the Effects of Modern Architecture on the Traditional Iranian Architecture}

In view of the above, examination of the effects of modern architecture on the traditional Iranian architecture, is necessary for re-development of the forgotten pattern of the Iranian people's life in the past periods as detailed below:

Architecture is among the components of the culture of any nation, which, considering the geographic situation, climatic characteristics, customs and traditions, values and opinions, are formed during the history and with time, and, when necessary, they change gradually and little by little as well.

Therefore, the architecture of any nation is specific to it and fitted to all parts of that nation and one could not make abrupt change in the architecture at once and merely for economic and political reasons.

Review of the effects of the modern architecture on the traditional Iranian architecture requires a concise knowledge of the traditional architecture. As said, an issue related to urban planning is present in the traditional Iranian architecture, which is important, and is the orientation of the house. Moreover, in the traditional Iranian architecture, many issues were being observed, for example, using insulation and the buildings being double coated, taking light from the roofs, using triple-door windows in order that the light could not penetrate the douse, and many other fine and accurate points that existed in it. 
The prominent Iranian architecture indicators are: balance, equilibrium, excellence, unity, clarity and being clear-cut, symbolism and mystification (of course, not signifying complexity and complication of the work and the designer's self-expression, but signifying giving identity and moral value to anything and anybody) and, generally, Iranian architecture is based on the following five principles (Pirnia 2001, 26-36):

1) Anthropomorphism: meaning having a human scale, similarly, all aspects of human dimensions were being observed.

2) Avoiding from absurdity: in Islamic architecture, using unnecessary elements was avoided and, at the same time, aesthetics was being observed.

3) Statics and strength of materials

4) Self-sufficiency: meaning the use of local materials. This had three important results: first, more speed in carrying out the works; second, conformity of the building to the natural environment and third, availability of the material anytime the building needs maintenance and repair.

5) Introversion: due to Iran's having a special geographic status, cultural issues and the codes of faith, and especially for the issue of privacy and observation of the realm of the family, the Iranian residential architecture is introverted. (Fig.4)

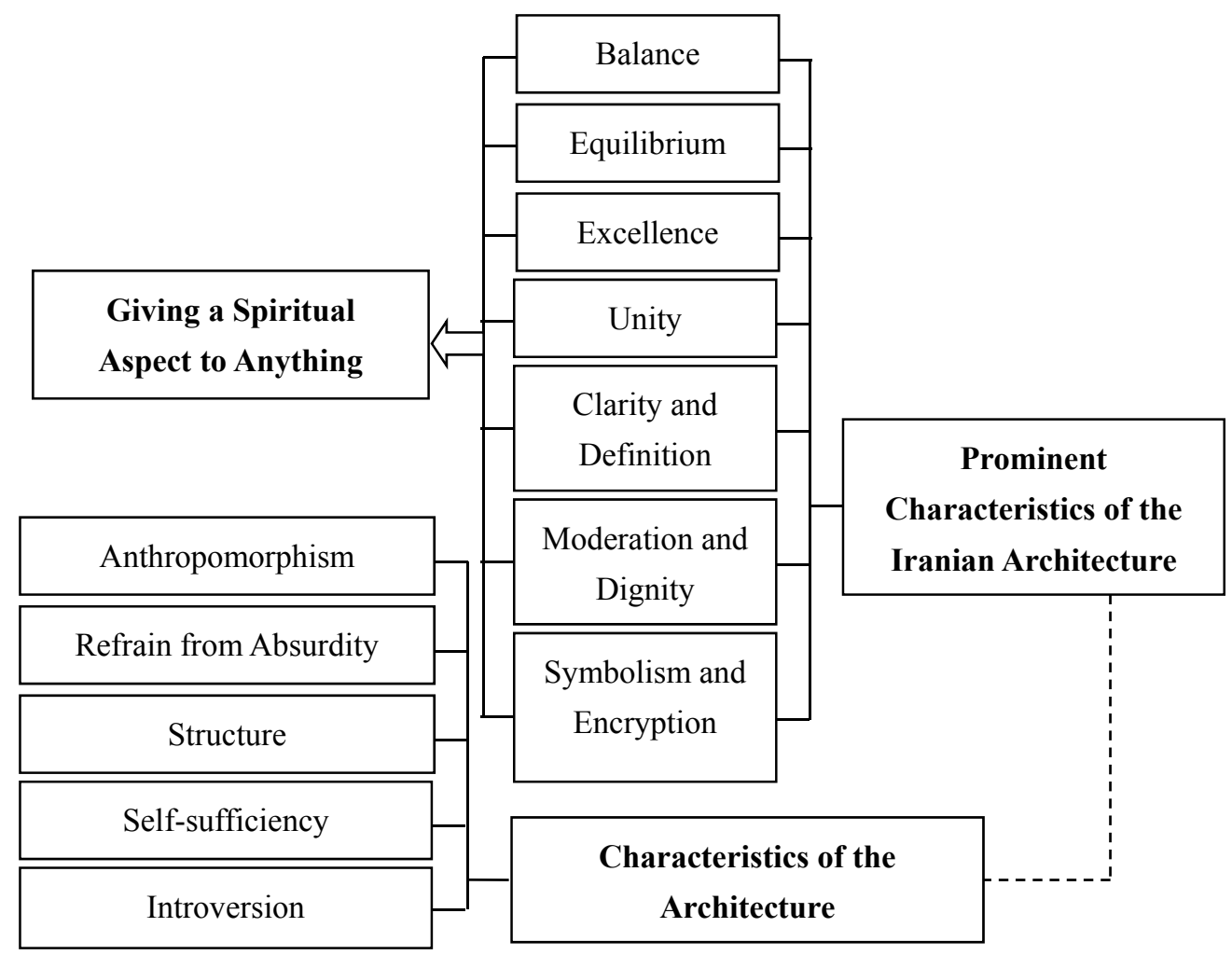

Figure 4. Spiritual aspect of the Iranian Architecture and its physical features

Now, one should see which changes have been brought in it by the western architecture.

What are being called a negative effect are the changes caused by blind imitation and sometimes arbitrary innovations in the new buildings.

However, one cannot claim that all the effects of the western model had been negative and harmful.

While, in principle, one of the objectives of modern architecture was the use of simple methods and industrial products, so that one could, using those methods increase the speed of construction.

\section{Evaluation and Comparison of the Traditional and Modern Residential Architectures in Iran}

The chaos of the city, the image of today cities and the subsequent lack of identity in architecture can be traced to the following factors (Nasr, Majedi 2013-2014, 274):

1) Incompatibility paradigm of modern architecture with traditional vernacular architectural patterns in the image 
of the cities;

2) Effect of criteria of comprehensive and detailed plans in the image of Iranian cities.

Unfortunately, the separation appearing in our culture led to separation of the relation between the concept of our culture and our architectural space. Our present day architectural space, due to various reasons, is not built based on our cultural space.

Therefore, in view of what said, one could conclude that housing has various social, economic, cultural and psychological dimensions, and one cannot look at it one-dimensionally. Therefore, the quality and the quantity of housing are both important. And since the satisfaction of the consumer ultimately is the most important, housing must be fitted to their traditional values, environmental, ideological and cultural and social values. The house must be a place for rest, comfort, and security, where the stresses, and fatigues and anxieties of the external ambient are removed. Thus, the house must accord to the psychological, social, biologic and cultural characteristics of man, so as it can be relaxing and indeed a place for relief, not a factor for intensifying the mental stresses of without.

Another issue that concerns the western architecture and the traditional Iranian architecture, is the fact that, first, western architecture is commensurate to the geographical conditions and the cultural values of the same nation, and, therefore, it could not and should not be imitated in its entirety and "as it is". Second, the traditional Iranian architecture, too, though commensurate to the special climatic conditions and cultural values of Iran, but could not respond to the requirements of the present day life in its classic form, since observation of the time contingencies and the modern life, too, are equally as important as geographical and cultural requirements. The problem resides in the fact that when taking as model from others, which perhaps are successful for their own sake and are more commensurate to the time, the culture, the values and the special conditions of the Iranian culture have not been involved in it. Our present day architectural spaces are not commensurate to our Iranian culture and life style at all; having an architectural culture is one of the missing links in our culture.

Of important points is the buildings architecture that in our country and especially in metropolitans is not in a good condition. The second issue is the identity of buildings that, considering the architecture in common use here, one could say easily that, not only those buildings do not give an identity to the city, but take its historical, past identity away from it. The third point that could be mentioned is the issue of safety.

So, significant components of the comparison between traditional and contemporary architecture can be explained (Fig.5).

\begin{tabular}{|c|}
\hline Comparison of traditional and modern house in Iran \\
\hline Conversion the house to shelter \\
\hline excessive Component or holistic thinking \\
\hline Quantity rather than quality control \\
\hline lack of dynamism and flexibility in space \\
\hline Pandemic of checkerboard texture \\
\hline Lack of collective living context \\
\hline uniformity with Turbulence in the context of standards \\
\hline
\end{tabular}

Figure 5. Comparison of traditional and modern house in Iran

\section{Re-Development of the Model of Local Life in Iran}

This viewpoint is given from two aspects (Nasr 2012):

\subsection{The Urban View; New Images and Identity Cues}

For making new images and identity cues, one should pay more attention to the issue of visual clarity or readability in the present day urban aspect that is somehow ignored. Indeed, the identity is the missing link in the present day construction works and this ignored principle has led to the fact that the figure of architecture and urban building in most cities of the country become somehow identity-less while the city had a culture-based architecture (Nasr 2005, 70).

Significant components in pathological image of today contemporary Iranian residential architecture are shown in Fig.6. 


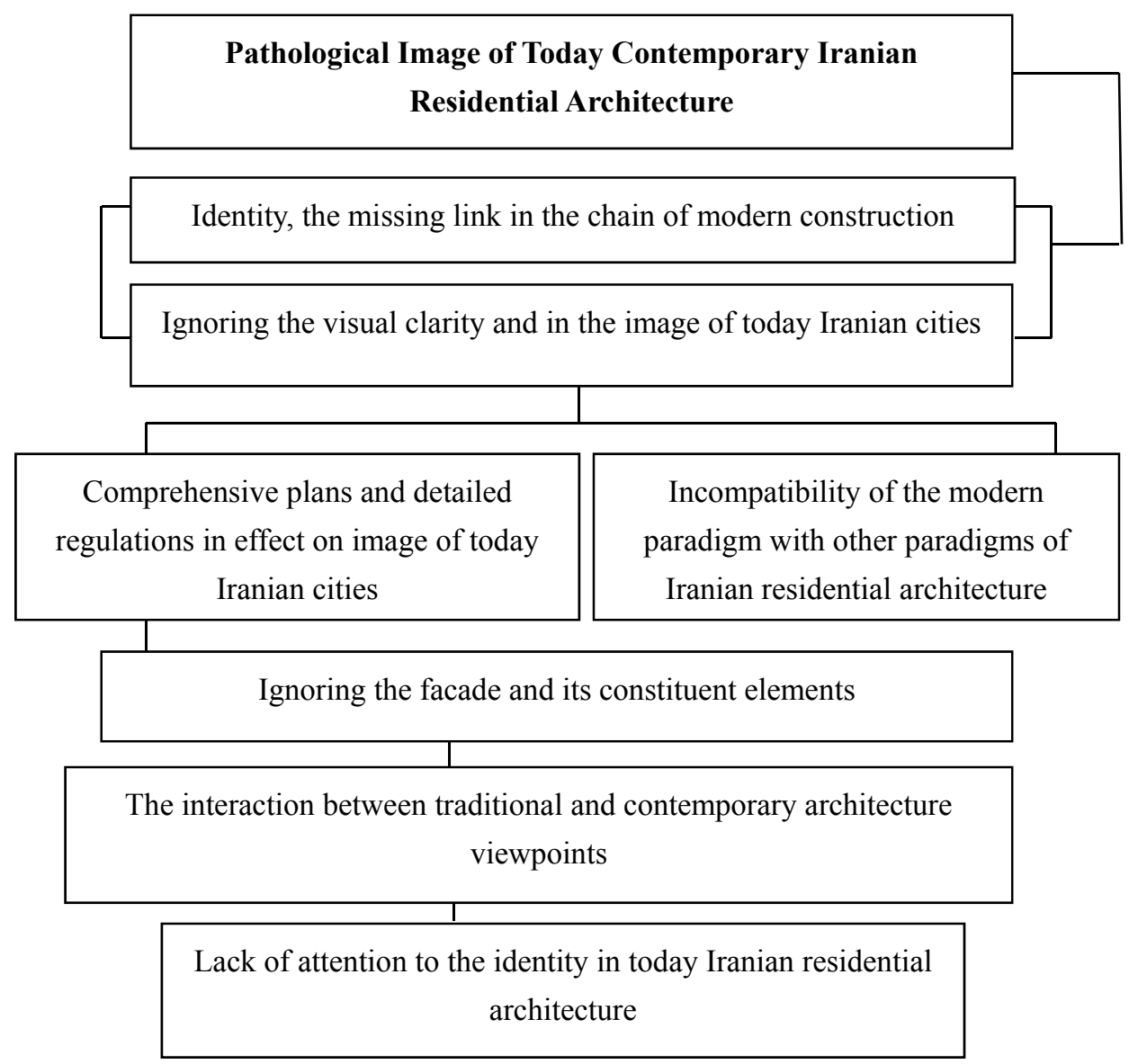

Figure 6. Pathological image of today contemporary Iranian residential architecture

Consideration of physical characteristics of the city in the country, too, can be effective in making identity images and cues, although finding common physical characteristics of the cities of the country is much difficult, but one can describe some characteristics common among the cities:

\subsection{The Architectural View}

\subsubsection{Architectures for Designing Appropriate Housing in a Residential Complex}

Providing criteria for designing appropriate housing in a residential complex will be achievable by comparing inseparable physical and functional structure of the traditional architecture, the way the housing is designed in the present time and in the following cases (Haeri Mazandarani 2009, 176-187) (Fig.7):

1) In the modern architecture, any of the spatial organizations of houses is designed as independent from the ambient around it. The panorama and the light in the modern house are not mandatory. However, in the historical house, the unlimited space is the feeding source of architecture and paying attention to the open space was mandatory.

2) In the modern architecture, the structure is formed independent from the space and is added to the space organization like a separate layer; that is while in the traditional housing, the structure is formed in coordination with the spatial organization.

3) The systems for heating comfort in the modern house are adjoined to the building; while in historical housing, the comfort giving factors such as wind catchers, the cellar, the shading, the water pool, the domestic garden, are incorporated into the spatial organization in an integrated form.

4) The courtyard is not defined in the modern house and even is turned into a place for parking cars; however, in the historical house it is used as the most genuine open space and represents symbiosis with the nature.

5) In the modern house, increasing the indoor space (courtyard) in the form of rooms, in any dimension is carried out; but in the historical there has been the possibility connecting the closed and the open spaces; 
6) Spaces like the balcony and the porch exist in few numbers in the modern house while in the historical house, it is used as the most genuine open space with observation of the realm, and it was the panorama to a vast open space.

7) There is no order for the sizes of door and the entrance to the doors; however, in the historical house, much attention was given to anthropomorphism;

8) Inconsistency in urban façade is frequent in modern buildings; however, in the historical house, this was not the case.

9) Light was an important factor in the historical house as evidenced by the presence of beautiful windows; however, in the modern building, paying attention to the natural light is minimal.

10) The wall in the modern house only serves to separate the spaces while in the historical house; the walls are constructed by producing mass.

11) The ceiling, regarding height, and the capability of being double coated, in the last story in the historical building, is in full contrast to the ceiling in the modern building in which everywhere the height is the same.

12) The passage realms in historical houses are fully apparent but in the modern house, it is not the case.

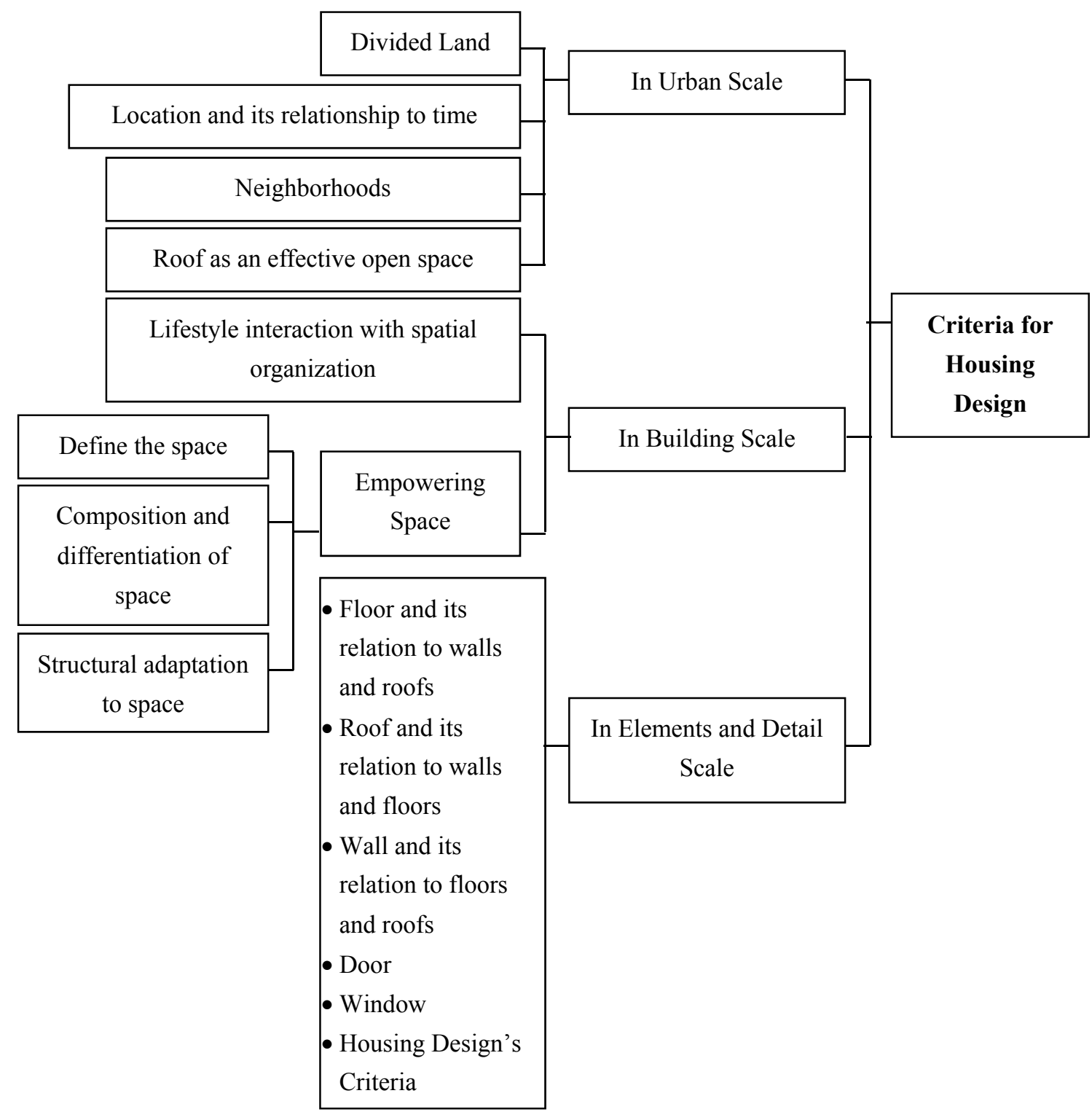

Figure 7. Criteria for housing design 


\section{Conclusion}

1) Regarding methodology, the terms Islamic "city" or Islamic architecture, in which "Islam" has been used as an adjective, especially in a professional discussion context, does not work well; architecture and Islam, both as two essences, must be referred to. The identity of the city as a complete set of unwritten patterns, beyond the temporal, spatial and cultural differences is recognizable.

The adjective "Islamic" beside architecture and urban planning, represents Islam as a civilization, not a religion; and the interpretations of the faith of Islam by Muslim nations during ages and its turning to models for urban planning and architecture are fully contextual and one should not generalize the absoluteness of fundamentals of Islam to the cultural and technical achievements of Muslim nations as well. The main characteristics of Islamic urban planning and architecture reside not in their creation of new elements and models but in how they are applied, organized and combined.

2) The first and the most effective factor affecting the observer is the appearance of the city, the quality of which is much affected by the facades of buildings and the facades of residential complexes. The façade design (such as traditional façade, modern façade, etc.) is the most effective factor in creation of a visual effect which is effective in that scale (such as different architectural dimensions and the ratio of the architectural space to the human body size), and proportions (such as dimensions of windows corresponding to dimensions of and the height of the building).

Other factors such as the way of construction (the main façade $\mathrm{f}$ the building being in screen, cement, masonry, steel, concrete form, etc.), the building structure (dome and arch in traditional Iranian architecture, steel joists or shell structures in modern architecture), and materials being used in the façade (brick, stone, cement, concrete or steel), the colour and the fabric of material and skill in construction (masonry, tiling, etc.), too, are effective in leaving a visual impact.

3) The present day teachings for housing construction that are based on the productivity view and looks at nature as a source of power that could be utilized until the stability is not at risk, and all the power that man obtains from nature must be used without any waste. The house itself is a place that responds to man's need, that is, the need for settlement and since it is constructed by man, such implications have emerged.

4) Selection of an appropriate executive method and choosing a justified construction system has always been one of the issues faced by executors of plans and managers and consulting engineers of construction projects. In that direction, one must, while classifying and explaining the major construction methods, and comparing them with one another, a final decision must be made regarding selection of an optimal construction method by providing tables that summarize the conditions for initial start, the heights of floors, the economic items, access to raw materials, durability and the useful life of the building, resistance to earthquakes, the manpower, machines, tools, construction time, the relative cost, form constraints, its conformity with construction codes, etc.

5) In the framework of providing the space required for man's comfort, housing is not only a material entity the realization of which entails engineering knowledge, but is also a spatial quality that serves to satisfy the psychological and mental needs of human beings as well. In that framework, in addition to a single housing unit, housing units, the neighborhood, the village and the city are regarded as housing as well.

6) The requirements of success of residential complexes are achieving an architecture and urban planning in harmony with the climate, the culture and the economy of the community. Housing plays a major role in satisfying many needs of man. The success of large residential projects resides in achieving an appropriate urban planning and architecture by paying attention to the role and the importance of housing in the life of man that is discussed briefly in what follows:

a) Shelter: the first important function of housing is nothing but provision of a shelter for the individuals. A shelter that can bring together the members of a family and by granting them comfort and peace of mind, taking them immune to physical and mental damage.

b) Economic value: it seems that the economic contribution of housing in the earlier communities has been less than that of today. In the present day, housing, by being turned into a capital and production asset, has taken the form of a fast return economic concept.

c) The social function: this function of housing is regarded as its prominent functions. Improper housing or its lacking in addition to affecting those who are in direct contact with it, leaves disruptive effects on the community as well. Deprival from housing in the future will lead to the phenomenon of slums living and sleeping by the street and insecurity in the foundation of the family, each of which can in turn expose the individual to types of abnormal behaviour and crimes. 
d) Mental function: an appropriate housing is a place for reaching comfort, recuperation, improvement in mental stresses and a place for stabilization of man's body and mind peace. Lack of housing or having a non standard housing is an important factor in the onset of types of mental stress, stresses leading to discomfort, depression and mental disorders in the individuals.

e) Employment: among other results of housing being a capital asset is its contribution to employment. This is an obvious fact that when housing turns into a manufacturing, commercial product, people will attempt residential building construction and this itself will provide employment opportunities for other layers of the community.

In the Athena charter, solutions for reducing the housing problem in housing projects have been given as follows:

1. Occupation density commensurate to the natural terrain conditions

2. Specifying the minimum hours required for each house to enjoy sunshine

3. Utilizing modern technical facilities for construction of high rising buildings for a better landscape, healthier air, more light, and the possibility for providing open, service spaces around the homes.

7) Speakers of the community express the expectation of the community from architecture and urban planning with general terms such as "identity" or "local model". However, references to identity images all belong to the past. For making new identity images ad cues, some invisible stages of exchange and change between the culture, opinions, traditions, usages, habits, techniques, the present day crafts, and the form of artifacts, including architecture, must be passed that are impossible except in the light of coordination between the collection of political, cultural, and economic powers and institutions.

The following items could assist in making new identity images and cues:

a) Our residential architecture could not be entirely an imitation of the western architecture or remain entirely in its traditional form. It would rather to be an integration of the traditional architecture and the technology of the present day, observing the points relating to the modern life as well as the cultural values and the climatic conditions and utilize the positive characteristics of both of them.

b) There is no room for creativity and variety in modern homes. If they are designed such that they are more flexible and more amendable to change, living in them will get easier. Of course, in addition to design of the house, inside it, too, one could use mobile walls for making change and variety in them.

c) Using and promoting local architecture by authorities who control construction is not taken seriously which has a major effect on lowering the quality of architecture in our country.

d) In addition, transformation must occur in educational centers, thinking and vision must be changed for achievement of the final ideal which is integration of the architectural style of the past with the modern one.

e) The local architecture is need that is being mentioned by many. It is not a transitional need; it is a historical need; the general orientation of art, architecture and urban planning in the west has a quite partial and materialistic approach under the influence of western thinking foundations and, at most, re-reads and regenerates the construction industry for us, while in the culture of our community, anything is a means for man's reaching his development; the whole universe, too, is a means for development of man; architecture and urban planning are being paid attention indeed for this same reason; therefore, in the art and in architecture, instead of the artist being self-founding, a new definition of architecture must be provided that is humanistic and emerges towards meeting the natural needs of people.

8) For making new identity images and cues, one must pay more attention to the issue of visual clarity or readability in the urban aspect of the present day that has been ignored somehow. Indeed, identity is the missing link in the present day constructions, and this ignored principle has led to the situation that the appearance of architecture and urban planning of most cities of the country become free from any identity while in a time the city in Iran had a culture-based architecture.

Considering the physical characteristics of the city in the country, too, can be effective in making new identity images and cues. Though finding common physical characteristics of cities in the country is much difficult, but, anyway, one can describe some common features among these towns with good accuracy.

Considering what said, one could describe the aspect of a genuine city of the country as follows:

In a genuine Iranian city, any phenomenon assists in promotion of motion and moral living; and different effects and symbols in the streets, parks and urban orchards and any other place in the city, while creating attraction, 
make the background for tendency of citizens towards moral things and in urban constructions, traditional architecture is paid attention as well and the buildings are constructed such that they remind us of Iranian living. Thus, paying attention to the urban identity, economic and social aspects of the city, basics of a healthy town and the spatial categories is much important.

Examination of a city entails definition of its distinctive features. For this case, one can resort to modelling that could be made in different ways. Setting criteria and regulations as well as information organization regarding control and care and procedures for urban management and providing the background for people's participation is significant.

\section{References}

Ardalan, N. (2010). Habitat Bill of Rights. Tehran, Iran: Yadavaran Press.

Corbusier, L. (1946). Maniera di pensare l'urbanistica. Roma, Italy: Laterza publications.

Haeri Mazandarani, M. R. (2009). House in Culture \& Nature of Iran. Tehran, Iran: Studies and Research Center of Planning and Architecture Publications.

Majedi, H. (2010). Buildings Urban Adaptation Planning. $1^{\text {st }}$ National Conference on Building's facades \& Image of City, Iran: Tehran, Municipality of Tehran.

Moore, C. (1974). The Place of House. California, USA: University of California Press.

Nasr, T. (2005). A Look on Identification in Architecture. International Road \& Structure Monthly Magazine, 31, 69-73.

Nasr, T. (2011). Evaluation of contemporary Iranian housing architecture. $1^{\text {st }}$ National Conference on Iranian Housing, Iran: Shiraz, Islamic Azad University.

Nasr, T. (2012). Planning for housing development and its architecture (By Considering the Evolution of Iranian Architecture). $1^{\text {st }}$ National Conference on Architecture \& Identification, Iran: Hamedan, Construction Engineering Organization.

Nasr, T., \&Majedi, H. (2013-2014). The significance of "identity" in urban planning. Armanshahr architecture and urban development seasonal journal, 11, 269-278.

Pirnia, M. K. (1995). Introduction to Iranian Islamic Architecture. Tehran, Iran: University of Science and Technology Publications.

Pirnia, M. K. (2001). Style of Iranian Architecture. Tehran, Iran: Pajouhandeh-Memar publications.

Rapoport, A. (1969). House Form and Culture. USA: Prentice Hall publications.

Sartipipoor, M. (2004). Housing Problems in Iran: A Pathological Review. SOFFEH, 39, 23-43.

Whittick, A. (1974). Encyclopedia of Urban Planning. McGraw-Hill Company, New York, London.

\section{Copyrights}

Copyright for this article is retained by the author(s), with first publication rights granted to the journal.

This is an open-access article distributed under the terms and conditions of the Creative Commons Attribution license (http://creativecommons.org/licenses/by/4.0/). 